\title{
Income distribution, socioeconomic status, and self rated health in the United States: multilevel analysis
}

\author{
Bruce P Kennedy, Ichiro Kawachi, Roberta Glass, Deborah Prothrow-Stith
}

\begin{abstract}
Objective: To determine the effect of inequalities in income within a state on self rated health status while controlling for individual characteristics such as socioeconomic status.

Design: Cross sectional multilevel study. Data were collected on income distribution in each of the 50 states in the United States. The Gini coefficient was used to measure statewide inequalities in income. Random probability samples of individuals in each state were collected by the 1993 and 1994 behavioural risk factor surveillance system, a random digit telephone survey. The survey collects information on an individual's income, education, self rated health and other health risk factors.

Setting: All 50 states.

Subjects: Civilian, non-institutionalised (that is, non-incarcerated and non-hospitalised) US residents aged 18 years or older.

Main outcome measure: Self rated health status. Results: When personal characteristics and household income were controlled for, individuals living in states with the greatest inequalities in income were $30 \%$ more likely to report their health as fair or poor than individuals living in states with the smallest inequalities in income.

Conclusions: Inequality in the distribution of income was associated with an adverse impact on health independent of the effect of household income.
\end{abstract}

\section{Introduction}

Inequalities in health associated with socioeconomic status are large and they are growing. Most theories that explain these inequalities use indicators of socioeconomic status associated with the individual such as income, educational attainment, or occupation. $^{1-4}$ A new hypothesis focuses on the distribution of income within a society as a predictor of health. ${ }^{5}$ Numerous ecological studies have provided support for this hypothesis showing that unequal distributions of income are associated with mortality in populations and life expectancy both between and within nations. ${ }^{5-9}$

These ecological studies indicate that inequalities in income may have extraindividual or contextual effects that structure the social environment in ways that affect the health of a population. ${ }^{10-12}$ It is not clear at what level of analysis the contextual effects of income inequality are best specified (for example, state, county, or neighbourhood) and whether it is more appropriate to test these using multilevel analyses (for example, of the state and individual) that can account for confounding variables at the level of the individual. Researchers have suggested that the relation between income distribution and mortality in populations may be due to a statistical artefact produced from the curvilinear relation of individual income to mortality. ${ }^{13}$ Oth- ers have argued that models using ecological data are more prone to model misspecification due to a greater likelihood of unmeasured confounding variables at the individual level. ${ }^{14}$ In a multilevel study that used both individual and ecological variables Fiscella and Franks found that the ecological effect of inequalities in income measured at the community level on mortality disappeared after controlling for family income. ${ }^{14}$ They concluded that previous studies using purely ecological variables may have overstated the relation between inequalities in income and mortality in populations as other studies had not controlled for the confounding of individual income.

This study was conducted to examine income inequalities measured by state to predict individual morbidity, as measured by self rated health status, while adjusting for potentially confounding individual variables. The potential confounding variables measured included household income, educational attainment, age, sex, race, whether an individual had health insurance, whether an individual smoked, and whether an individual was obese. Using a multilevel model that includes both ecological variables (in this case income distribution within a state) and individual variables militates against the possibility of model misspecification and the attribution of a contextual effect where none exists. ${ }^{15} 16$

\section{Data and methods}

\section{Sources of data}

Data on individuals' reported health status, income, demographic variables, and access to health care were drawn from the results of the combined 1993-4 survey of the behavioural risk factor surveillance system. The telephone survey is conducted by state health departments under the direction of the Behavioral Surveillance Branch of the National Center for Chronic Disease Prevention and Health Promotion, Centers for Disease Control and Prevention. The states use probability samples in which all households with telephones have a non-zero chance of inclusion; the samples are designed to produce comparable estimates for the civilian, non-institutionalised (that is, non-incarcerated and non-hospitalised) population aged 18 or older.

In 1993 questions about health as related to quality of life were added. From the question about perceived health (Would you say that in general your health is: excellent, very good, good, fair, or poor ${ }^{\text {?7}}$ ) we created a dichotomous outcome measure equal to 1 if the respondent answered fair or poor. A review of 27 studies has shown that this simple measure of self rated health has strong predictive validity for mortality, independent of other physiological, behavioural, and psychosocial risk factors. ${ }^{18}$ Furthermore, it has been shown in longitudinal studies that self rated health predicts the onset of disability. ${ }^{19-23}$
Division of Public Health Practice, Harvard School of Public Health, 718 Huntington Avenue, Boston, MA 02115, USA Bruce P Kennedy deputy director Roberta Glass, research specialist Deborah Prothrow-Stith, professor

Department of Health and Social Behavior, Harvard School of Public Health

Ichiro Kawachi, associate professor

Correspondence to: Dr Kennedy kennedy@hsph. harvard.edu

BMJ 1998;317:917-21 
Demographic data collected by the survey included information on race, age, sex, educational attainment, and household income. The proportion of people reporting fair or poor health remains relatively constant until age 40 and then increases linearly. To model this relation we created a variable that measures the number of years a respondent is older than age 40 . Educational attainment was categorised as having less than a high school education, having a high school education, having attended some university or a trade school, or being a university graduate. Measures of access to health care included determining whether the person had health insurance and whether the person had had a health check up visit within the past two years. Household composition was categorised as one adult living alone, two or more adults with no children, one adult with any children, and two or more adults with children. Race was categorised as white, black, or other. Annual household income was categorised as $<\$ 10000, \$ 10000$ to $\$ 14999, \$ 15000$ to $\$ 19999$, $\$ 20000$ to $\$ 24999, \$ 25000$ to $\$ 34999, \$ 35000$ to $\$ 49000$, and $\geqslant \$ 50000$.

For our variable on income inequality we used data on the Gini coefficient. ${ }^{24}$ The Gini coefficient is constructed using data on household income from the population survey for the years 1990-2. Income data are adjusted for differences among states in taxes and cash transfers as well as differences in household composition using an equivalence scale (with the equivalence elasticity 0.5 ). The sample was divided into four categories based on the distribution of the coefficient. Category 1 represents the states with small inequalities in income and includes states with coefficients less than one standard deviation below the mean coefficient for the United States (0.332). This included nine states with coefficients <0.320: Connecticut, Delaware, Hawaii, Iowa, North Dakota, South Dakota, Utah, Vermont, and Wisconsin. Category 2 included 13 states with coefficients between one standard deviation below the mean and the mean $(0.320$ to 0.331): Indiana, Kansas, Maine, Maryland, Minnesota, Montana, Nebraska, New Mexico, Ohio, Oregon, Pennsylvania, Rhode Island, and Wyoming. Category 3 included 18 states with coefficients between the mean and one standard deviation above the mean (0.3320.355): Alaska, Arizona, Arkansas, Colorado, Idaho, Massachusetts, Michigan, Missouri, Nevada, New Hampshire, New Jersey, North Carolina, Oklahoma, South Carolina, Tennessee, Virginia, West Virginia, and Washington. Category 4 includes the states with the greatest inequalities in income (coefficients $>0.355$ ): Alabama, California, Florida, Georgia, Illinois, Kentucky, Louisiana, Mississippi, New York, and Texas.

\section{Analysis of data}

The behavioural risk factor surveillance system uses a three stage sampling design, which requires special statistical techniques to account for clustering when calculating standard errors. All logistic regression procedures were calculated using Software for Survey Data Analysis (SUDAAN, version 5.50, Research Triangle Institute, Research Triangle Park, NC) which takes the survey design into account when estimating standard errors. It can also be used for multilevel models using clustered data (such as for individuals within states). The estimation procedure takes into account the viola- tion of independence among individuals in the same cluster (state) and estimates the appropriate standard errors.

Logistic regression was used to examine the relation between state income inequality and self reports of fair or poor health while controlling for an individual's household income. A second logistic regression model examined the same relation while adjusting for the demographic characteristics of age, sex, and race. A third model adjusted for factors that might be pathways through which inequalities in income influence health status. These additional factors included health insurance status, recent use of healthcare services, household composition, smoking status, obesity, and educational attainment. Finally, we stratified the sample by household income and by race (white, black, or other) and used adjusted models to determine whether the relation between health status and income inequality differed by income or race.

\section{Results}

The total sample size for the combined 1993-4 datasets was 205245 , ranging from a total of 1259 responses in Wyoming to 8800 in Maryland. The percentage of respondents within a state reporting fair to poor health was strongly correlated with mortality within the state $(r=0.58)$.

Table 1 summarises characteristics of the respondents and bivariate relations with reported fair or poor health. Women were slightly overrepresented in the sample ( $58.3 \%$ women $v 41.7 \%$ men). In simple bivariate analyses, more women reported fair or poor health than men (15.4\% v 13.1\%), as did blacks compared to whites $(20.3 \% \mathrm{v} 13.8 \%)$. In the bivariate associations income was strongly associated with fair or poor health; for the whole sample, $32 \%$ of those in the lowest income category $(<\$ 10000)$ reported fair or poor health compared to only $6.3 \%$ in the highest income category $(>\$ 35000)$. This represented a fivefold gradient effect for household income on health. A similar gradient was seen for education: $45 \%$ of those with no education or with less than a high school education reported fair or poor health compared with $6 \%$ of university graduates. Obesity, smoking, household composition, health insurance coverage, and other demographic variables were also associated with fair or poor health.

Table 2 shows the multivariate odds ratios for the effects of income inequality on health. The unadjusted odds ratio of the Gini coefficient for income inequality shows that there is an increased risk of about $30 \%$ for fair or poor health for individuals living in states with greater inequalities in income. This effect is attenuated when household income is added to the model but the odds ratios remain significant (table 2). The effect remains fairly stable even after adjusting for demographic variables and risk factors. The effect of income inequality on health in the fully adjusted model stratified by race was similar for blacks (adjusted odds ratio for the states with the greatest income inequality 1.37 , $95 \%$ confidence interval 1.08 to 1.74 ) and for whites $(1.27,1.19$ to 1.36$)$ (table 2). Although women reported being in fair or poor health slightly more often than men $(15.4 \% v .13 .1 \%)$ this difference was not significant 
in the fully adjusted model (odds ratio for men 1.05, 1.00 to 1.09$)$ (table 2).

We also examined the effects of income inequality stratified by household income (table 3). The effects of income inequality on health were most pronounced among those whose incomes were $<\$ 20000$; those in this category had about a $30 \%$ increase in the risk of fair or poor health in the states with the greatest inequalities in income. These effects remained stable after adjusting for a variety of individual characteristics. Inequalities in income were also associated with an increased risk of reporting fair or poor health in about $20 \%$ of those in the middle income group (\$20000 to \$35000) although this was not as pronounced as among those in the lower income group. These effects remained stable after adjusting for other risk factors.

\section{Discussion}

Fiscella and Franks found that the ecological effect of income inequality at the level of the community disappears after including family income in a model. ${ }^{14}$ Contrary to Fiscella and Franks, we found an independent effect of income inequality on reported health after adjusting for potentially confounding individual variables, including household income. Furthermore, the effect of income distribution, although attenuated somewhat, did not change significantly when household income was included in the model. When stratified by income the effects of inequalities in income were strongest among those with lower incomes. The income inequality variable did not have a significant effect on the reported health of those in the highest income group yet the effect was present for those in the middle income group.

Fiscella and Franks suggested that earlier findings from ecological studies may have been confounded by individual income. ${ }^{14}$ They suggested that income inequality was capturing the compositional effect of individual income on mortality-that is, areas with more poor individuals have greater inequalities in income and, since being poor is associated with higher mortality, there is a spurious association between income inequality and mortality. Our findings do not support their conclusions but suggest that there is an independent contextual effect of income distribution, measured at state level, on individual ratings of health.

There are a number of potential explanations for the differences between our findings and those of Fiscella and Franks. Firstly, they used a different level of aggregation which may have been too small to allow income distribution to exert an effect independent of individual income. It is not clear at what ecological level income inequality can be expected to be meaningful. For example, income inequality measured within very poor and very affluent communities would not have the same meaning as inequalities was measured across them. As Wilkinson points out, it is not the inequality within Harlem that matters but how Harlem compares with the larger society. ${ }^{25}$

Secondly, this study used self rated health as the outcome; this variable may be more sensitive to income inequality. However, studies have shown that self rated health is linked to mortality. This measure of self rated
Table 1 Characteristics of 205245 respondents and number reporting fair or poor health

\begin{tabular}{|c|c|c|}
\hline Characteristic & No (\%) & $\begin{array}{l}\text { No }(\%) \text { reporting fair or } \\
\text { poor health }\end{array}$ \\
\hline Male & $85505(41.7)$ & $11222(13.1)$ \\
\hline Female & $119740(58.3)$ & $18457(15.4)$ \\
\hline \multicolumn{3}{|l|}{ Health } \\
\hline \multicolumn{3}{|l|}{ Smoking status: } \\
\hline Smoker & $46859(22.8)$ & $7972(17.0)$ \\
\hline Non-smoker & $157901(76.9)$ & $21606(13.7)$ \\
\hline Information missing & $485(0.2)$ & $101(20.8)$ \\
\hline \multicolumn{3}{|l|}{ Body mass: } \\
\hline Obese & $53283(26.0)$ & $10938(20.5)$ \\
\hline Not obese & $151962(74.0)$ & $18741(12.3)$ \\
\hline \multicolumn{3}{|l|}{ Health insurance coverage: } \\
\hline Yes & $179872(87.6)$ & $25484(14.2)$ \\
\hline No & $24874(12.1)$ & $4134(16.6)$ \\
\hline Information missing & $499(0.2)$ & $61(12.2)$ \\
\hline \multicolumn{3}{|l|}{ Health check up in past 2 years: } \\
\hline Yes & $166903(81.3)$ & 25852 (15.5) \\
\hline No & $38342(18.7)$ & $3827(10.0)$ \\
\hline \multicolumn{3}{|l|}{ Self rated health: } \\
\hline Excellent & $50452(24.6)$ & - \\
\hline Very good & $68538(33.4)$ & - \\
\hline Good & $56118(27.3)$ & - \\
\hline Fair & $21231(10.3)$ & - \\
\hline Poor & $8448(4.1)$ & - \\
\hline Information missing & $458(0.2)$ & - \\
\hline \multicolumn{3}{|l|}{ Household } \\
\hline \multicolumn{3}{|l|}{ Size: } \\
\hline 1 person & $50395(24.6)$ & $10798(21.4)$ \\
\hline 2 people & $66120(32.2)$ & $10448(15.8)$ \\
\hline 3 people & $35044(17.1)$ & $3780(10.8)$ \\
\hline 4 people & $31818(15.5)$ & $2555(8.0)$ \\
\hline 5 people & $13925(6.8)$ & $1200(8.6)$ \\
\hline 6 people & $4930(2.4)$ & $517(10.5)$ \\
\hline$\geqslant 7$ people & $2755(1.3)$ & $350(12.7)$ \\
\hline Information missing & $258(0.1)$ & $31(12.0)$ \\
\hline \multicolumn{3}{|l|}{ Composition: } \\
\hline One adult, no children & $50395(24.6)$ & $10798(21.4)$ \\
\hline One adult and children & $14129(6.9)$ & $1717(12.2)$ \\
\hline Two or more adults and children & $64376(31.4)$ & $5339(8.3)$ \\
\hline Two or more adults, no children & $76345(37.2)$ & $11825(15.5)$ \\
\hline Any children & $78505(38.3)$ & $7056(9.0)$ \\
\hline No children & $126482(61.6)$ & $22592(17.9)$ \\
\hline Information missing & $258(0.1)$ & $31(12.0)$ \\
\hline \multicolumn{3}{|l|}{ Annual income (\$): } \\
\hline$<10000$ & $29099(14.2)$ & $9165(31.5)$ \\
\hline $10000-14999$ & $18516(9.0)$ & $4329(23.4)$ \\
\hline 15 000-19 999 & $17670(8.6)$ & 2916 (16.5) \\
\hline $20000-24999$ & $18760(9.1)$ & $2412(12.9)$ \\
\hline 25 000-34999 & $29015(14.1)$ & $2669(9.2)$ \\
\hline $35000-49999$ & $30781(15.0)$ & $1929(6.3)$ \\
\hline$\geqslant 50000$ & $35500(17.3)$ & $1554(4.4)$ \\
\hline Information missing & $25904(12.6)$ & $4705(18.2)$ \\
\hline \multicolumn{3}{|l|}{ Gini coefficient } \\
\hline$<0.320^{*}$ & $34690(16.9)$ & $4365(12.6)$ \\
\hline $0.320-0.331$ & $52536(25.6)$ & $6923(13.2)$ \\
\hline $0.332-0.335$ & $70541(34.4)$ & $10634(15.1)$ \\
\hline$>0.335 \dagger$ & $47478(23.1)$ & $7757(16.3)$ \\
\hline \multicolumn{3}{|l|}{ Educational attainment } \\
\hline No school & $1504(0.7)$ & $326(21.7)$ \\
\hline Less than high school or no school & $10919(5.3)$ & $4915(45.0)$ \\
\hline Some high school & $18032(8.8)$ & $5508(30.5)$ \\
\hline High school graduate or equivalent & $67995(33.1)$ & $10321(15.2)$ \\
\hline Some university or technical school & $55038(26.8)$ & $5537(10.1)$ \\
\hline University graduate & $51295(25.0)$ & $2950(5.8)$ \\
\hline Information missing & $462(0.2)$ & $122(26.4)$ \\
\hline \multicolumn{3}{|l|}{ Race } \\
\hline White & $176037(85.8)$ & $24312(13.8)$ \\
\hline Black & $17346(8.5)$ & $3517(20.3)$ \\
\hline Other & $11614(5.7)$ & $1824(15.7)$ \\
\hline Information missing & $248(0.1)$ & $26(10.5)$ \\
\hline
\end{tabular}

*States with the smallest inequalities in income. †States with the greatest inequalities in income. 
Table 2 Odds ratios (95\% confidence intervals) for respondents reporting fair or poor health. Level of inequalities in income is adjusted for characteristics of the respondents

\begin{tabular}{|c|c|c|c|c|}
\hline Independent variables & Unadjusted odds ratio & $\begin{array}{l}\text { Odds ratio adjusted for } \\
\text { household income }\end{array}$ & $\begin{array}{c}\text { Odds ratio adjusted for } \\
\text { household income, sex, } \\
\text { and race }\end{array}$ & $\begin{array}{l}\text { Odds ratio adjusted for } \\
\text { household income, sex, } \\
\text { race, and all other } \\
\text { variables }\end{array}$ \\
\hline \multicolumn{5}{|l|}{ Gini coefficient: } \\
\hline$>0.355^{\star}$ & 1.32 (1.25 to 1.39$)$ & $1.23(1.16$ to 1.30$)$ & $1.27(1.19$ to 1.34$)$ & 1.25 (1.17 to 1.33$)$ \\
\hline $0.332-0.355$ & 1.29 (1.22 to 1.35$)$ & $1.23(1.17$ to 1.30$)$ & 1.28 (1.21 to 1.36$)$ & 1.25 (1.18 to 1.32$)$ \\
\hline $0.320-0.331$ & $1.19(1.13$ to 1.26$)$ & $1.14(1.07$ to 1.21$)$ & $1.15(1.08$ to 1.23$)$ & $1.11(1.04$ to 1.18$)$ \\
\hline$<0.320 \dagger$ & 1.00 & 1.00 & 1.00 & 1.00 \\
\hline \multicolumn{5}{|l|}{ Annual income (\$): } \\
\hline$<10000$ & & 7.43 (6.99 to 7.89$)$ & 5.38 (5.05 to 5.74$)$ & 3.40 (3.16 to 3.65$)$ \\
\hline $10000-14999$ & & 5.32 (5.03 to 5.75$)$ & 3.93 (3.65 to 4.22$)$ & 2.65 (2.45 to 2.86$)$ \\
\hline $15000-19999$ & & 3.62 (3.37 to 3.89 ) & 2.84 (2.63 to 3.06$)$ & 2.05 (1.89 to 2.21$)$ \\
\hline $20000-24999$ & & 2.71 (2.51 to 2.92) & 2.26 (2.09 to 2.44$)$ & 1.76 (1.63 to 1.91) \\
\hline $25000-35000$ & & 1.98 (1.84 to 2.12) & 1.81 (1.69 to 1.95) & 1.52 (1.41 to 1.63) \\
\hline$>35000$ & & 1.00 & 1.00 & 1.00 \\
\hline Unknown & & 3.76 (3.52 to 4.01$)$ & 2.60 (2.43 to 2.79$)$ & 2.01 (1.87 to 2.16$)$ \\
\hline Age (years older than 39) & & & 1.04 (1.04 to 1.04) & 1.04 (1.04 to 1.04) \\
\hline Male & & & $1.06(1.02$ to 1.10$)$ & 1.05 (1.00 to 1.09$)$ \\
\hline \multicolumn{5}{|l|}{ Race: } \\
\hline Black & & & 1.54 (1.45 to 1.63$)$ & $1.32(1.25$ to 1.41$)$ \\
\hline Other & & & $1.43(1.32$ to 1.55$)$ & $1.36(1.26$ to 1.48$)$ \\
\hline Smoker & & & & 1.52 (1.45 to 1.59$)$ \\
\hline Obese & & & & 1.75 (1.68 to 1.83$)$ \\
\hline Have health insurance & & & & $0.79(0.74$ to 0.84$)$ \\
\hline Had health check up in the past 2 years & & & & 1.36 (1.28 to 1.43$)$ \\
\hline \multicolumn{5}{|l|}{ Education: } \\
\hline Less than high school & & & & $1.72(1.63$ to 1.81$)$ \\
\hline Some university & & & & $0.79(0.75$ to 0.83$)$ \\
\hline University graduate & & & & 0.54 (0.51 to 0.58$)$ \\
\hline \multicolumn{5}{|l|}{ Household composition: } \\
\hline Lives alone & & & & 0.91 (0.87 to 0.95$)$ \\
\hline One parent family & & & & 0.91 (0.84 to 0.99$)$ \\
\hline Two parent family & & & & $1.00(0.95$ to 1.06$)$ \\
\hline
\end{tabular}

${ }^{*}$ States with the greatest inequalities in income.

†States with the smallest inequalities in income.

health has high predictive validity for mortality. ${ }^{18}$ In this study self rated health aggregated to the level of the state was strongly correlated with the total age adjusted mortality rates for the state $(r=0.58)$ and the correlation with the Gini coefficient, although larger, was similar to that of mortality $(0.62 v 0.51)$.

Another reason for the divergence in findings may be due to measurement error in the calculation of income inequality. As Fiscella and Franks noted their samples were not meant to be representative of the communities to which the ecological variables were assigned..$^{14}$ Furthermore, the measures of inequality were derived from the distribution of income for each area's sample and were truncated at $\$ 25000$. This may have resulted in an underestimation of the true degree of inequality and thus attenuated its effects in the

Table 3 Odds ratio (95\% confidence interval) of Gini coefficient for each model for respondents reporting fair or poor health. Level of income inequality is adjusted for individual characteristics and stratified by income

\begin{tabular}{|c|c|c|c|c|}
\hline \multirow[b]{2}{*}{ Model } & \multicolumn{4}{|c|}{ Gini coefficient } \\
\hline & $<0.320^{*}$ & $0.320-0.331$ & $0.332-0.355$ & $>0.355 \dagger$ \\
\hline \multicolumn{5}{|l|}{ Annual income $<\$ 20000$} \\
\hline Unadjusted model & 1.00 & $1.16(1.06$ to 1.26$)$ & $1.26(1.16$ to 1.36$)$ & $1.29(1.19$ to 1.40$)$ \\
\hline \multicolumn{5}{|l|}{ Adjusted for: } \\
\hline Age, sex, and race & 1.00 & 1.18 (1.08 to 1.29$)$ & $1.32(1.22$ to 1.44$)$ & 1.39 (1.28 to 1.52$)$ \\
\hline Age, sex, race, and all other variables & 1.00 & 1.11 (1.01 to 1.22$)$ & $1.25(1.15$ to 1.36$)$ & $1.33(1.22$ to 1.45$)$ \\
\hline \multicolumn{5}{|l|}{ Annual income $\$ 20000-35000$} \\
\hline Unadjusted model & 1.00 & $1.11(0.97$ to 1.26$)$ & $1.30(1.16$ to 1.46$)$ & $1.18(1.04$ to 1.34$)$ \\
\hline \multicolumn{5}{|l|}{ Adjusted for: } \\
\hline Age, sex, and race & 1.00 & $1.13(0.99$ to 1.30$)$ & 1.36 (1.20 to 1.53$)$ & 1.19 (1.05 to 1.36$)$ \\
\hline Age, sex, race, and all other variables & 1.00 & $1.11(0.97$ to 1.27$)$ & 1.35 (1.19 to 1.52$)$ & $1.20(1.05$ to 1.37$)$ \\
\hline \multicolumn{5}{|l|}{ Annual income $>\$ 35000$} \\
\hline Unadjusted model & 1.00 & $1.13(0.98$ to 1.31$)$ & $1.08(0.94$ to 1.24$)$ & $1.13(0.98$ to 1.31$)$ \\
\hline \multicolumn{5}{|l|}{ Adjusted for: } \\
\hline Age, sex, and race & 1.00 & 1.14 (0.98 to 1.32) & 1.07 (0.93 to 1.23) & $1.08(0.93$ to 1.25$)$ \\
\hline Age, sex, race, and all other variables & 1.00 & 1.13 (0.98 to 1.32$)$ & 1.07 (0.93 to 1.24$)$ & 1.09 (0.94 to 1.27$)$ \\
\hline
\end{tabular}

${ }^{*}$ States with the smallest inequalities in income.

†States with the greatest inequalities in income. 
Key messages

- Inequalities in the statewide distribution of income are associated with self rated fair or poor health, even after individual income and other risk factors are accounted for

- The effects of income distribution on self rated health were not limited only to those in the lowest income groups; those in the middle income groups in states with the greatest inequalities in income rated themselves as having poorer health than those in middle income groups in states with the smallest inequalities

- The effects of income inequality on self rated health are as strong as other individual risk factors

- Social and economic policies that affect income distribution may have important consequences for the health of the population

multilevel model. A more appropriate index of income inequality could be derived from income data from an independent source such as census data from the county (as was done in this study).

\section{Conclusion}

Inequalities in income at the state level exert an independent effect on an individual's risk of reporting fair or poor health. This suggests that the ecological relation between income inequality and mortality is not simply an artefact caused by the compositional effect of aggregated individual incomes. ${ }^{13}{ }^{14}$ There seems to be a clear contextual effect of income inequality on health status.

Gravelle $^{14}$ argued that the effect of income inequality on the risk of death was an artefact resulting from the non-linear shape of the relation between average income and mortality rates and the use of aggregate rather than individual data (the ecological fallacy). Years ago we suggested that the non-linear relation between average income and mortality is a sufficient but not necessarily the only explanation for the association between inequalities in income and health. ${ }^{26}$ This multilevel analysis suggests that the association is not a product of the ecological fallacy and that a contextual effect of income inequality is apparent even among individuals whose personal incomes are above the poverty line. Social and economic policies that affect income distribution may have important consequences for population health.

We thank Professor Timothy Smeeding for providing data on the Gini coefficient.

Contributors: This study was based on the core ideas of BPK and IK. They assume primary responsibility for the design of the study, interpretation of the findings, and the writing of the paper. RG participated in designing the study, performed all of the data analysis, and participated in writing the paper. DP-S discussed the paper's core ideas, assisted with the interpretation of the findings, and participated in the writing of the paper.

Funding: BPK and IK are recipients of Robert Wood Johnson Foundation investigator awards in health policy research.

Conflict of interest: None.
1 Black D, Morris JN, Smith C, Townsend P, Whitehead M. Inequalities in health: the Black report. London: Penguin, 1988.

2 Smith GD, Shipley MJ, Rose G. Magnitude and causes of socioeconomic differentials in mortality: further evidence from the Whitehall study. $J$ Epidemiol Community Health 1990;44:265-70.

3 Pappas G, Queen S, Hadden W, Fisher G. The increasing disparity in mortality between socioeconomic groups in the United States, 1960 and 1986. N Engl J Med 1993;329:103-9.

4 Adler NE, Boyce T, Chesney MA, Cohen S, Folkman S, Kahn RL, et al. Socioeconomic status and health: the challenge of the gradient. Am Psychol 1994;49:15-24.

5 Wilkinson RG. Income distribution and life expectancy. $B M J$ 1992;304:165-8.

6 Wilkinson RG. Unhealthy societies: the afflictions of inequality. London: Routledge, 1996

7 Kennedy BP, Kawachi I, Prothrow-Stith D. Income distribution and mor tality: cross sectional ecological study of the Robin Hood index in the United States [correction appears in BMJ 1996;312:1194]. BMJ 1996;312:1004-7

8 Kaplan GA, Pamuk ER, Lynch JW, Cohen RD, Balfour JL. Inequality in income and mortality in the United States: analysis of mortality and potential pathways. BMJ 1996;312:999-1003.

9 Ben Shlomo Y, White IR, Marmot M. Does the variation in the socioeconomic characteristics of an area affect mortality? BMJ 1996;312:1013-4.

10 Wilkinson RG. Health inequalities: relative or absolute material standards. BMJ 1997;314:591-5.

11 Smith, GD. Income inequality and mortality: why are they related? $B M$ 1996;312:987-8.

12 Kawachi I, Kennedy BP, Lochner K, Prothrow-Stith D. Social capital, income inequality, and mortality. Am J Public Health 1997;87:1491-8.

13 Gravelle H. How much of the relation between population mortality and unequal distribution of income is a statistical artefact? $B M J$ 1998;316:382-5.

14 Fiscella K, Franks P. Poverty or income inequality as predictor of mortality: longitudinal cohort study. BMJ 1997;314:1724-7.

15 Blalock H. Contextual effects models: theoretical and methodological issues. Am Rev Sociol 1984;10:353-72.

16 Hauser R. Contextual effects models: a cautionary tale. Am J Sociol 1970;75:645-64.

17 Hagan HC, Moriarty DG, Zack MM, Scherr PA, Brackbill R. Measuring health-related quality of life for public health surveillance. Public Health Rep 1994;109:665-72.

18 Idler El, Benyamini Y. Self-rated health and mortality: a review of twentyseven community studies. J Health Soc Behav 1997;38:21-37.

19 Ferraro KF, Farmer MM, Wybraniec JA. Health trajectories: long-term dynamics among black and white adults. J Health Soc Behav 1997;38:38-54.

20 Idler EL, Kasl S. Self-ratings of health: do they also predict change in functional ability? J Gerontol B Psychol Sci Soc Sci 1995;50B:S344-53.

21 Mor V, Murphy J, Materson-Allen S, Willey C, Razmpour A, Jackson ME, et al. Risk of functional decline among well elders. J Clin Epidemiol 1989;42:895-904

22 Wilcox VL, Kasl SV, Idler EL. Self-rated health and physical disability in elderly survivors of a major medical event. J Gerontol B Psychol Sci Soc Sci 1996;51B:S96-104.

23 Farmer MM, Ferraro KF. Distress and perceived health: mechanisms of health decline.J Health Soc Behav 1997;39:298-311.

24 Atkinson $\mathrm{AB}$, Rainwater L, Smeeding TM. Income distribution in $O E C D$ countries: evidence from the Luxembourg income study. Paris: Organisation for Economic Cooperation and Development, 1995.

25 Wilkinson RG. Income inequality summarises the health burden of individual deprivation. BMJ 1997;314:1728-9.

26 Kawachi I, Levine S, Miller SM, Lasch K, Amick B. Income inequality and life expectancy: theory, research and policy. Boston: New England Medical Center, 1994. (Joint Program on Society and Health, working paper No 94-2.)

(Accepted 18 June 1998)

\section{Endpiece \\ Serendipidity}

Unknown diseases seem to yield to surgical treatment applied to them by accident, and these unexpected successes may some day lead us on the road to other victories, but how these are to be achieved we cannot as yet say.

Lawson Tait, "The surgery of the liver" (1889)

Submitted by Ann Dally, Wellcome Institute for the History of Medicine 